\title{
AS (MULTIPLI)CIDADES DOS MODERNISTAS PORTUGUESES
}

\author{
THE MULTIPLE CITIES OF PORTUGUESE \\ MODERNISTS
}

\author{
La Salette Loureiro"
}

L'artiste authentique moderne voit la metrópole comme de la vie abstraite figurée... le naturel, dans la ville, est toujours atténué et régularisé par l'esprit humain... Le beau s'y exprime d'une manière plus mathématique. La ville est donc le lieu à partir duquel doit se développer le tempérament artistique de l'avenir.

Mondrian, De Stil, n. ${ }^{\circ}$ 1, 1918, p. $132^{1}$.

RESUMO: Tal como os seus congéneres europeus, também os modernistas portugueses, Fernando Pessoa, Almada e Sá-Carneiro, elegeram a cidade como tema de muitos dos seus textos. Porém, mesmo quando se trata de uma mesma cidade real, Lisboa ou Paris, a cidade de cada um deles é substancialmente diferente. Nesta comunicação abordaremos dois tópicos relacionados com o tema da cidade em dois destes autores. Assim, para Pessoa/ Bernardo Soares, trataremos de duas faces da mesma moeda, «A cidade do quotidiano» e «A cidade irreal», para Sá-Carneiro, destacaremos a relação do autor e suas personagens com a cidade de Paris.

Palavras-chave: cidade, Fernando Pessoa, Mário de Sá-Carneiro

Abstract: Like other European artists, also the Portuguese modernists, Fernando Pessoa, Almada and Sá-Carneiro, elected the city as the subject of many of their writings. But even when it comes to the same real city, Lisbon or Paris, the city of each of them is substantially different. This paper will cover two topics related to the theme of the city in two of these authors. So for Pessoa / Bernardo Soares, we will deal with "The city of daily life" and "The unreal city", to Sá-Carneiro, the author's relationship and his characters with the city of Paris.

KeYwords: City, Fernando Pessoa, Mário de Sá-Carneiro

\footnotetext{
"Mestrado em Literatura Comparada Portuguesa e Francesa, pela Universidade Nova de Lisboa; Licenciatura em Línguas e Literaturas Modernas: Estudos Portugueses e Franceses, pela Universidade de Coimbra. E-mail: 1sloureiro@sapo.pt.

${ }^{1}$ Apud Wladimir Krisinski. Entre Aliénation et Utopie: La ville dans la Poésie Moderne. In: AAVV. La Ville n'est pas un lieu. Rev. Esthétique, nº 3/4. Paris: Un. Gen. Editions, 1977, p. 31.
} 


\section{INTRODUÇÃO}

Em consonância com o que se passa na Europa na sequência da transformação urbana originada pela industrialização, também os modernistas portugueses, Pessoa, Almada e Sá-Carneiro, instituem a cidade como tema de muitos dos seus textos.

Verificamos, no entanto, que, mesmo quando se trata de uma mesma cidade real, como Lisboa ou Paris, e apesar de viverem num mesmo tempo e partilharem experiências comuns, os aspectos selecionados pelos diferentes autores são substancialmente diferentes, porque inquestionavelmente marcados pelas suas diferentes personalidades, vivências reais ou imaginárias, e sensibilidades. O que, aliás, vem confirmar a ideia de Italo Calvino de que "cada homem traz na mente uma cidade feita só de diferenças, uma cidade sem figuras e sem forma" (CALVINO, 1990, p. 36).

Pessoa dissertou largamente sobre o assunto e deixou que Álvaro de Campos e Bernardo Soares gravassem no papel as descrições, as reflexões e os sentimentos que as cidades, reais ou imaginárias, inspiravam.

A cidade de Campos é a Grande Metrópole cosmopolita, pejada de luzes e de multidões, de luxos e de progresso, mas também de um cortejo de misérias que este fatalmente engendra. Ela assume também dimensões metafísicas quando a define como o lugar para onde se vai e onde se fica, em contraste com a "aldeola do espaço", a Terra, onde vivemos transitoriamente. A cidade é também o lugar de encontro, ou desencontro, com os Outros e o palco onde a condição humana se lhe revela.
Também a cidade de Soares desempenha esta função, mas ela apresenta-se-lhe como uma escrita de signos incompreensíveis, que é forçoso decifrar para desvendar o mistério do Homem e do Universo. A cidade real serve-lhe ainda de porta de acesso para todas as cidades inexistentes que a sua imaginação inventa.

Sá-Carneiro admira deslumbradamente as grandes capitais, sente Paris como um corpo de mulher/amante, por ela suspira apaixonadamente, tal como as suas personagens.

Almada elege a cidade como o lugar de encontro de cada um consigo mesmo. É nela que os seus heróis aprendem, ou desaprendem, a ser homens.

Na senda de Cesário, Lisboa merece um destaque especial a todos estes autores, à excepção de Sá-Carneiro. Lisboa de Campos, duas vezes "revisitada" em busca da sua unidade perdida, Lisboa do cais, real ou simbólico, de chegada ou de partida, onde também ele tenta desvendar o sufocante enigma do Universo. Lisboa de Soares, do quotidiano colhido ao vivo nas ruas da Baixa, fruída pelos sentidos, mas impregnada de sentidos ocultos. Lisboa Lar, para ambos. Ou então, Lisboa de Almada, boémia e nocturna, de clubs e de cabarets, onde desfila uma sociedade mergulhada numa "apagada e vil tristeza", que lhe merece as mais duras críticas.

Nesta comunicação abordaremos dois tópicos relacionados com o tema da cidade em dois destes autores. Assim, para Pessoa/ Bernardo Soares, trataremos de duas faces da mesma moeda, "A cidade do quotidiano" e "A cidade irreal", para Sá-Carneiro, o tema 
da relação do autor e suas personagens com Paris.

BERNARdo SOARES: LISBOA NO QUOTIDIANO (A RUa dos Douradores)

Bernardo Soares escreve no Livro do Desassossego "A minha consciência da cidade é, por dentro, a minha consciência de mim" (PESSOA, 1986, p. 163), mostrando assim que a exploração da cidade coincide com a exploração do seu próprio Eu.

Morador num quarto alugado na Rua dos Douradores ${ }^{2}$, sobre a cidade e o infinito, ajudante de guarda-livros no escritório da mesma rua, "transeunte de corpo e alma" pelas ruas da Baixa e do sonho, Soares é um digno sucessor do seu constante e comovidamente evocado e invocado mestre, Cesário Verde. Como ele passeante anónimo e atento, mesmo quando distraído, Soares faz da sua errância por LISBOA (intencionalmente grafada a maiúsculas) um verdadeiro exercício dos sentidos.

A sua Lisboa é a cidade do quotidiano, onde a náusea, o tédio e o gozo se misturam com todas as cores, todos os sons e todos os cheiros que sobre ela pairam diariamente. É desse mergulho diário que o Livro do Desassossego nos fala, numa sempre comovida fruição da alma e dos sentidos, mas sobretudo destes últimos, nomeadamente, da visão, sentido hipervalorizado, a que outros

\footnotetext{
2 "E, se o escritório da Rua dos Douradores representa para mim a vida, este meu segundo andar, onde moro, da mesma rua dos Douradores, representa para mim a Arte" (PESSOA, 1986, p. 228). N.B.: Em vários textos do Livro do Desassossego o quarto onde mora é no $4 .^{\circ}$ andar. Ex: "O aplauso chega ao quarto andar onde moro" (Ibid., p. 216).
}

dois, ouvido e olfacto se associam. Bernardo Soares vê com o ouvido e também o olfacto é para ele "uma estranha vista". O tacto e o gosto são desvalorizados, por menores e carnais ${ }^{3}$. Mas todos eles podem agir em simultâneo, à boa maneira de Cesário e dos Simbolistas.

Os sentidos, porém, são ainda outros. São os significados que vêm das coisas e das gentes, dum Universo cifrado que Bernardo Soares, tal como Álvaro de Campos, não se cansa de procurar desvendar. São ainda os sentidos com que ele próprio investe as coisas e os seres e com os quais procura representar o Mundo e o Homem.

Mas antes de mais e acima de tudo, podemos dizer que a Lisboa de Bernardo Soares é uma cidade amada, configurando-se como um "foyer au sens affectif, pour lequel on éprouve des sentiments ambivalentes", como afirma Alexander Mitscherlich (MITSCHERLICH, 1970, p. 175). Os verbos "amar" e "gozar", conjugados na primeira pessoa do singular, normalmente relacionados com a contemplação ou a errân$\mathrm{cia}^{4}$, aparecem constantemente no Livro do Desassossego ${ }^{5}$.

Nesse sentido, parece-nos que a análise de Alexander Mitscherlich se aplica na

\footnotetext{
3 "Ver e ouvir são as únicas cousas nobres que a vida contém. Os outros sentidos são plebeus e carnais. A única aristocracia é não tocar” (Ibid., p. 218).

${ }^{4}$ Eis alguns exemplos: "gozo de sentir-me coevo de Cesário Verde" (Ibid., p. 55), "gozo de errar sem pensar entre o que a cidade se torna” (Ibid., p. 108), "Gozo o céu” (Ibid., p. 195).

5 "Amo, pelas tardes demoradas de Verão, o sossego da cidade baixa” (Ibid., p. 55), "e amo-vos da amurada” (Ibid., p. 87), "Amo esses largos solitários" (Ibid., p. 151), "amo o Tejo” (Ibid., p. 195), são apenas alguns exemplos.
} 
perfeição ao caso de Bernardo Soares, quando aquele diz que "Le moi peut aller jusqu'à inclure en lui la ville natale ou aussi la ville “élue" (MITSCHERLICH, 1970, p. 49), ou então:

Quand tout se passe bien, une ville devient un objet d'amour; [...] La ville est réconfort et consolation dans le désespoir, un décor joyeux pour les jours de fête; elle représente, dans la diversité de ses fonctions, quelque chose de plus ancien que le monde paternel, elle est, dans les beaux exemples que nous connaissons tous, l'amante mère, un être dont on ne peut se détacher car on reste éternellement son enfant, ou son tendre compagnon (Ibid., p. 41).

Assim, a cidade de Bernardo Soares desempenha a função protectora de mãe, que lhe é tradicionalmente atribuída e é visível na designação moderna de metrópole, metro (mãe) + polis. Por isso nos deixou declarações como "Oh, Lisboa, meu lar!" (PESSOA, 1986, p. 99) e "Se eu tivesse o mundo na mão, trocava-o, estou certo, por um bilhete para a Rua dos Douradores" (Ibid., p. 206).

Quanto à cidade do quotidiano, verifica-se que, no $2^{\circ}$ ou no $4^{\circ}$ andar da Rua dos Douradores (é significativo que vida e arte morem na mesma rua), pela Rua da Prata, da Alfândega, do Arsenal, dos Fanqueiros, pela Praça da Figueira, pelo Terreiro do Paço, com o Tejo sempre ao fundo, um céu em permanente metamorfose policromática, e todas as paisagens que os olhos da alma alcançam, vive Bernardo Soares a sua "nula", "vida quotidiana de transeunte incógnito" (Ibid., p. 235).
O seu dia a dia é constituído pelo trabalho, as refeições no restaurante ${ }^{6}$, as estadas no café, a deambulação pela cidade, a meditação, a escrita, o sonho diário. Tudo é igual, regular, vulgar e monótono, como, aliás, tudo aquilo que o rodeia ${ }^{7}$. E é vivido às vezes, quase sempre, num estado de semi-consciência ${ }^{8} \mathrm{e}$ alheamento'.

Tal regularidade e monotonia provoca naturalmente uma sensação de tédio, (embora este seja uma tendência natural do Sujeito ${ }^{10}$ ), de náusea, de frustração e até de humilhação, como ilustram alguns trechos:

Sim, vejo nitidamente, com a clareza com (que) os relâmpagos da razão destacam do negrume da vida os objectos próximos que no-la formam, o que há de vil, de lasso, de deixado e factício, nesta Rua dos Douradores que me é a vida inteira - este escritório sórdido até à sua medula de gente, este quarto mensalmente alugado onde nada acontece senão viver um morto, esta mercearia cujo dono conheço como gente conhece gente, estes moços da porta da taberna antiga, esta inutilidade trabalhosa de todos os dias iguais, esta repetição pegada das mesmas personagens,

\footnotetext{
6-"não comi bem, nem bebi o costume, no restaurante, ou casa de pasto, em cuja sobreloja baseio a continuação da minha existência” (Ibid., p. 189).

7-"o armazém, até à Rua dos Douradores, enfileira as prateleiras regulares, os empregados regulares, a ordem humana e o sossego do vulgar. Na vidraça há o ruído do diverso, e o ruído diverso é vulgar" (Ibid., p. 57).

8-"Não sei se estou com febre, como sinto, se deixei de ter a febre de ser dormidor da vida" (PESSOA, 1986, p. 65).

9-"Passa tudo isso, e nada de tudo isso me diz nada, tudo é alheio ao meu sentir" (Ibid., p. 56).

10- "Em mim o tédio é frequente, mas, que eu saiba, porque reparasse, não obedece a regras de aparecimento" (Ibid., p. 131).
} 
como um drama que consiste apenas no cenário, e o cenário estivesse às avessas (Ibid., p. 293).

A peregrinação constante pelas ruas constitui, de certo modo, uma forma de lutar contra estas sensações desagradáveis e, algumas vezes, assume mesmo um carácter intencional ${ }^{11}$. Mas ela é também um ensejo de observação e meditação $0^{12}$. Assim, é através delas que o autor/personagem nos dá informações sobre a paisagem física e humana e também sobre as suas paisagens interiores que, em alguns casos, prolongam ou reproduzem as exteriores. Como uma objectiva móvel ou fixa, pronta a disparar a qualquer momento ${ }^{13}$, Soares vai focando a massa humana que desfila à sua frente. Mas também a azáfama das ruas é registada: os carroceiros carregando os caixotes ${ }^{14}$, as vendedeiras, os jornais do dia, a agitação colorida da Praça da Figueira, os moços de fretes fingindo que trabalham ${ }^{15}$.

\footnotetext{
"Um dos meus passeios predilectos, nas manhãs em que temo a banalidade do dia que vai seguir como quem teme a cadeia, é o de seguir lentamente pelas ruas fora, antes da abertura das lojas e dos armazéns, e ouvir os farrapos de frases que os grupos de raparigas, de rapazes, e de uns com as outras, deixam cair, como esmolas da ironia, na escola invisível da minha meditação aberta" (Ibid., p. 74).

${ }^{12-}$ Ver nota anterior.

13-"Sigo por uma rua como quem está sentado, e a minha atenção, desperta a tudo, tem todavia a inércia de um repouso do corpo inteiro" (Ibid., p. 258).

14 "Na rua cheia de caixotes vão os carregadores limpando a rua. Um a um, com risos e ditos, vão pondo os caixotes nas carroças. Do alto da minha janela do escritório eu os vou vendo, com olhos tardos em que as pálpebras estão dormindo" (Ibid., p. 172).

15- "os moços de fretes estão a fazer não fazer nada, indeterminadamente” (Ibid., p. 173).
}

Continuar na Rua dos Douradores, isto é, igual a toda a gente, e muito aquém do sonho, parece ser uma fatalidade ${ }^{16}$ contra a qual, às vezes, o Sujeito se revolta ${ }^{17}$, e de que sente vontade de fugir ${ }^{18}$. Choca, porém, com obstáculos idiossincráticos intransponíveis: a sua inércia física, o seu medo do novo e do risco ${ }^{19}$.

Por outro lado, verificamos que, quando a rotina se altera, este se sente desconfortável e perdido, procurando mesmo reentrar nela, achando que "Era em certo modo o lar, isto é, o lugar onde se não sente” (Ibid., p. 277), ou como diz noutro fragmento "A vulgaridade é um lar. O quotidiano é materno” (Ibid., p. 271).

Verifica-se então que o quotidiano constitui uma espécie de lar, com todos os valores afectivos que lhe estão associados, uma espécie de protecção maternal e anestesiante, de que, apesar dos protestos, Soares precisa para se sentir minimamente confortável e seguro ${ }^{20}$.

Aliás, a realidade quotidiana, aquilo a que ele chama vida, constituída pelo mundo exterior, que ele adjectiva, à maneira de

\footnotetext{
16- "A escravatura é a lei da vida, e não há outra lei, porque esta tem de cumprir-se, sem revolta possível nem refúgio que achar" (Ibid., p. 106).

17- "Serei sempre da Rua dos Douradores, como a humanidade inteira” (Ibid., p. 106).

18- "O meu desejo é fugir. Fugir ao que conheço, fugir ao que é meu, fugir ao que amo” (Ibid., p. 106).

19- "Nunca vou para onde há risco" (Ibid., p. 200); "Abomino a vida nova e o lugar desconhecido" (Ibid., p. 249); "A inacção consola de tudo. Não agir dá-nos tudo" (Ibid., p. 286).

20- "Seja onde estiver, recordarei com saudade o patrão Vasques, o escritório da Rua dos Douradores, e a monotonia da vida quotidiana será para mim como a recordação dos amores que me não foram advindos, ou dos triunfos que não haveriam de ser meus" (Ibid., p. 189).
} 
Caeiro, de "espantosa objectividade do mundo" (Ibid., p. 297), chega até a ser a única coisa suportável: "Tudo se me tornou insuportável, excepto a vida - o escritório, a casa, as ruas - o contrário até, se o tivesse - me sobrebasta e oprime" (Ibid., p. 297).

Esta problemática assume, portanto, um carácter de insolubilidade. Atracção e repulsa existem alternada e até simultaneamente. Porém, a balança pende muito mais para o lado da atracção, como mostra a passagem que a seguir reproduzimos, de acentuado sabor paúlico:

Ah, como as cousas quotidianas roçam mistérios por nós! Como à superfície, que a luz toca, desta vida complexa de humana [?], a Hora, sorriso incerto, sobe aos lábios do Mistério!

Que moderno que isto soa! (Ibid., p. 297).

E afinal, vendo bem as coisas, um dia chega à conclusão de que "Considerando bem tudo, prefiro o Moreira ao mundo astral; prefiro a realidade à verdade" (Ibid., p. 272). Obviamente, o sonho não deixa de ser um tempero indispensável e é ele que merece a designação de "verdade", mas, às vezes, "deixa um horror à vida interior, uma náusea física dos misticismos e das contemplações" (Ibid., p. 272). É então que o escritório e o Moreira se tornam num "porto" seguro ${ }^{21}$.

E afinal, o seu dia a dia de guarda-livros, e o seu convívio com o patrão Vasques, o Moreira e outros funcionários do escritório da Rua dos Douradores, não foram sem

${ }_{21}$ "Com que pressa corro de casa, onde assim sonhe, ao escritório; e vejo a cara do Moreira como se chegasse finalmente a um porto" (Ibid., p. 272). proveito para a elaboração deste seu livro "casual e meditado", constituindo antes uma boa fonte de inspiração:

Devo ao ser guarda-livros grande parte do que posso sentir e pensar como a negação e a fuga do cargo (Ibid., p. 226).

Se houvesse de inscrever, no lugar sem letras de resposta a um questionário, a que influências literárias estava grata a formação do meu espírito, abriria o espaço ponteado com o nome de Cesário Verde, mas não o fecharia sem nele inscrever os nomes do patrão Vasques, do guarda-livros Moreira, do Vieira caixeiro de praça e do António moço do escritório. E a todos poria, em letras magnas, o endereço chave LISBOA.

Vendo bem, tanto o Cesário Verde como estes foram para a minha visão do mundo coeficientes de correcção (Ibid., p. 226-7).

\section{BERNARDO SOARES: A CIDADE IRREAL}

Nestas circunstâncias, desgostoso da realidade e de si próprio, comprazendo-se na inaç̧ão, este Eu não tem outra saída senão a construção de um mundo imaginário, concebido à sua própria medida, uma cidade irreal. Mas para o conseguir precisa de analisar a realidade, pois como refere:

As cousas são a matéria para o meu sonho; por isso aplico uma atenção distraidamente sobreatenta a certos detalhes do Exterior. 
Para dar relevo aos meus sonhos preciso conhecer como é que as paisagens reais e as personagens da vida nos aparecem relevadas (Ibid., p. 53).

Assim, se "ver" é uma actividade que assume a máxima importância no Livro do Desassossego, ela é, por um lado, uma actividade selectiva, pois "A minha visão das coisas suprime sempre nelas o que o meu sonho não pode utilizar" (Ibid., p. 53), por outro lado, ela não é um exclusivo dos olhos do corpo. Ao contrário, é muitas vezes de olhos fecha$\operatorname{dos}^{22}$ que o Sujeito contempla as paisagens que mais o fascinam e que adquirem uma nitidez, às vezes, fotográfica, idêntica à daquelas que à vista se lhe oferecem: "Vejo as paisagens sonhadas com a mesma clareza com que fito as reais" (Ibid., p. 98).

Aliás, na sua óptica, o mundo sonhado é o que é realmente verdadeiro ${ }^{23} \mathrm{e}$ "sonhar é muito mais prático que viver” (Ibid., p. 86), opinião que coincide com Bachelard, para quem "Toujours, imaginer sera plus grand que vivre" (BACHELARD, 1957, p. 90). O onírico institui-se, assim, como "l'affirmation d'un temps et d'un lieu d'accomplissement", associando-se pelos efeitos que produz ao estatuto do "sagrado", tal como ele pode ser vivido na grande cidade, segundo a análise de Jean Rémy e Liliane Voyé. Com efeito, encontramos no Livro do Desassossego, uma prática do onírico/sagrado embebido na vivência do quotidiano (o primário), acrescentando a este um "surplus de sens", um suplemento de

\footnotetext{
22 "Se cerrar os olhos, continuo vendo, pois que não vejo" (PESSOA, 1986, p.154).

23 "O meu mundo imaginário foi sempre o único mundo verdadeiro para mim” (Ibid., p. 285).
}

sentido, que leva a uma realização total, absoluta, coincidente com algumas afirmações destes autores. Vejamos:

Il (le sacré) est ainsi en liaison étroite avec le registre onirique, lequel permet de composer divers élements de la vie quotidienne selon des modalités qui sont impossibles dans celle-ci.[...]

On peut, à partir de là, comprendre comment, en s'insérant dans la vie quotidienne, l'onirique peut exprimer une mise en question de celle-ci et comment aussi une des requêtes du sacré consiste en l'affirmation d'un temps et d'un lieu d'accomplissement où, au-delà des incompatibilités, existe une unité (RÉMY; VOYÉ, p. 80).

Ainsi peut-il (le sacré) donner des lieux de compensation dans l'imaginaire ou intégrer le primaire dans une poétique où il prend sens ou bien encore devenir refus et protestation (Ibid., p. 80-1).

Nesta perspectiva, considerando-se a si próprio como espectador e espectáculo, o "teatro íntimo" (PESSOA, 1986, p. 272) que Soares constrói dentro de si, só pode ser gratificante e compensador das frustrações "reais" duma vida incompleta, que lhe passa ao lado, "simples quadro externo", "- - bailado sem nexo, mexer de folhas ao vento, nuvens em que a luz do sol muda de cores, arruamentos antigos, ao acaso, em pontos desconformes da cidade" (Ibid., p. 111). É o que nos mostra uma passagem, que não deixa de nos lembrar o Universo em que se move o seu mais ou menos contemporâneo Sá-Carneiro: 
não sendo mais, nem querendo ser mais, que um espectador de mim, tenho que ter o melhor espectáculo que posso. Assim me construo a ouro e sedas, em salas supostas, palco falso, cenário antigo, sonho criado entre jogos de luzes brandas e músicas invisíveis (Ibid., p. 123-4).

Assim concebida, a actividade onírica é uma constante e institui-se, muitas vezes, em simultâneo com a observação da realidade ${ }^{24}$, com ela se fundindo ${ }^{25}$, como atrás dissemos. É num estado de sonolência que muitas vezes deambula pelas ruas, atentamente distraído, semi-virado para fora, semi ou completamente virado para dentro:

Quando durmo muitos sonhos, venho para a rua, de olhos abertos, ainda com o rastro e a segurança deles. E pasmo do automatismo meu com que os outros me desconhecem. Porque atravesso a vida quotidiana sem largar a mão da ama astral, e os meus passos na rua vão concordes e consoantes com obscuros desígnios da imaginação de dormir. E na rua vou certo; não cambaleio; respondo bem; existo.

[...] para evitar veículos ou não estorvar peões, quando não tenho que falar a alguém, nem me pesa a entrada para uma porta próxima, largo-me de novo nas águas do sonho [...] e de novo regresso à ilusão mortiça que me

\footnotetext{
24 "De maneira que a arte que queira representar bem a realidade terá de a dar através duma representação simultânea da paisagem interior e da paisagem exterior" (PESSOA, 1987, p. 157).

25 "Sigo, simultaneamente, pela rua, pela tarde e pela leitura sonhada, e os caminhos são verdadeiramente percorridos" (PESSOA, 1986, p. 108-9).
}

acalentara a vaga consciência da manhã nascendo entre o som dos carros que hortaliçam (Ibid., p. 92).

É neste estado semi-acordado que as ruas reais da Baixa se transformam nos grandes cenários da imaginação, écrans onde perpassam os filmes de vidas inexistentes: "E então, em plena vida, é que o sonho tem grandes cinemas. Desço uma rua irreal da Baixa e a realidade das vidas que não são ata-me, com carinho, a cabeça num trapo branco de reminiscências falsas" (Ibid., p. 92).

Não só as vidas, mas também as paisagens desfilam sob o seu olhar contemplativo. Todas as cidades e lugares acedem ao seu conhecimento pela sua fértil imaginação:

Passei por cidades mais que existentes, e os grandes rios de nenhuns mundos fluíram, absolutos, sob os meus olhos contemplativos (Ibid., p. 97).

Passeei pelas margens dos rios cujo nome me encontrei ignorando. Às mesas dos cafés de cidades visitadas descobri-me a perceber que tudo me sabia a sonho, a vago (Ibid., p. 26).

Por isso, já viu tudo, mesmo sem ter visto nada, isto é, sem ter viajado. E, afinal, para quê correr o risco da viagem, se "Para viajar basta existir" (Ibid., p. 223) e se "Quando se sente de mais, o Tejo é Atlântico sem número, e Cacilhas, outro continente, ou até outro universo" (Ibid., p. 223).

A sua vida é já uma viagem: "Vou de dia para dia, como de estação para estação, no comboio do meu corpo, ou do meu destino, debruçado sobre as ruas e as praças, sobre os gestos e os rostos, sempre iguais e sempre 
diferentes, como, afinal, as paisagens são" (Ibid., p. 223).

Por outro lado, basta-lhe apanhar o eléctrico, transporte para o corpo e para a alma, para que as cidades, os cafés, as gentes de todo o mundo, com as mais variadas profissões, desfilem diante da sua alma: "Os bancos do eléctrico, de um entre-tecido de palha forte e pequena, levam-me a regiões distantes, multiplicam-se-me em indústrias, operários, casas de operários, vidas, realidades, tudo" (Ibid., p. 139).

Também os passageiros do eléctrico lhe servem de passaporte para a construção do filme das suas vidas sociais e profissionais, o mesmo acontecendo com aqueles que, estando ausentes, têm presente o fruto do seu trabalho. Através dele, ele os vê de "olhos virados para dentro", correspondendo à ideia de Bachelard, quando este afirma que "lhomme est l'être entr'ouvert" (p. 200):

Vou num carro eléctrico, e estou reparando lentamente, conforme é meu costume, em todos os pormenores das pessoas que vão adiante de mim. [...] Nesse vestido da rapariga que vai em minha frente decomponho o vestido em o estofo de que se compõe, o trabalho com que o fizeram [...] desdobram-se diante de mim as fábricas e os trabalhos - a fábrica onde se fez o tecido; a fábrica onde se fez o retrós, [...]; e vejo as secções das fábricas, as máquinas, os operários, as costureiras, meus olhos virados para dentro penetram nos escritórios, vejo os gerentes procurar estar sossegados, sigo, nos livros, a contabilidade de tudo; mas não é só isto: vejo, para além, as vidas domésticas dos que vivem a sua vida social nessas fábricas e nesses escritórios ...

Todo o mundo se me desenrola aos olhos só porque tenho diante de mim [...] (Ibid., p. 139)

A sua própria vida também se constrói, ou reconstrói, em função das paisagens vistas, realizando os dons do poeta indicados por Baudelaire:

Cada casa por que passo, cada chalé, cada casita isolada caiada de branco e de silêncio - em cada uma delas num momento, me concebo vivendo, primeiro feliz, depois tediento, cansado depois; e sinto que, tendo-a abandonado, trago comigo uma saudade enorme do tempo em que lá vivi. [...]

Depois, ao passar diante de casas, de villas, de chalés, vou vivendo em mim todas as vidas das criaturas que ali estão (Ibid., p. 192).

Este processo de criação imaginária inclui a transfiguração completa do real, de modo a torná-lo exclusivamente seu, o que consegue forjando "um modo interior do exterior" (PESSOA, 1988, p. 69). Desta forma, confirma a frase de Bachelard "L'en dehors et l'en dedans sont tous deux intimes" (BACHELARD, 1957, p.196), uma atitude que ele chama "A Divina Inveja". No seu exemplo mais conseguido, transforma o Cais do Sodré num pagode chinês (PESSOA, 1988, p. 69).

Desta maneira, Bernardo Soares, frequentemente de costas voltadas para a realidade cinzenta, cria a sua própria cidade, uma cidade sonhada, mas, para ele, mais "real" que qualquer outra, porque "O sonhador é um emissor de notas, e as notas que emite 
correm na cidade do seu espírito do mesmo modo que as da realidade" (PESSOA, 1986, p. 87).

Quanto à outra realidade, ela não é, na sua mundividência, uma certeza adquirida. Sobre a sua "real" existência, ficam-lhe muitas dúvidas, ela aparece-lhe antes como "uma ficção ingénita” (Ibid., p. 237).

Assim sendo, está justificada a sua opção pelos sonhos, certamente mais gratificante e compensadora, apesar da pobreza que eventualmente lhes poderá advir dos modestos motivos que os inspiram, como humildemente pretende o seu autor, no final do livro, pois "até deste quarto andar sobre a cidade se pode pensar no infinito. Um infinito com armazéns em baixo, é certo, mas com estrelas no fim..." (Ibid., p. 318).

Mário de Sá-Carneiro: Paris cidade MULHER/ AMANTE

Mais do que qualquer outro dos seus companheiros de Geração que aqui analisamos, Mário de Sá-Carneiro sentiu a grande cidade como "grande teatro cosmopolita" (O Fixador de Instantes, SÁ-CARNEIRO, s.d., a), p. 191), amou e "estrebuchou" os Grandes Meios, amou e idolatrou a "Europa", com todas as conotações que esta palavra envolveu naquela época, erigiu-os seus deuses. As suas cidades são "rútilas de Europa, largas, pejadas de trânsito e movimentos - rendez-vous cosmopolitas, farfalhantes de acção" ${ }^{m_{6}}$ (SÁ-CARNEIRO, 1992, p. 251).

$\mathrm{Na}$ ânsia de tudo possuir, também volveu a cidade Mulher e a sentiu dentro de si:

${ }^{26}$ Carta a Fernando Pessoa, de 17/7/1915.
"O certo é que sinto Praças dentro de mim (Eu-Próprio o Outro, SÁ-CARNEIRO, s.d., a), p. 156), às vezes, até ao espasmo. Ungido de "errado", amou igualmente as suas virtudes e os seus vícios, mas, sobretudo, "zebrantemente", os seus vícios.

Poder-se-á dizer que a representação da cidade em Sá-Carneiro convoca como nenhuma outra as palavras de Pierre Sansot que a seguir reproduzimos:

Le bizarre, l'étrange, la divine rencontre, le goût parfois du sordide, l'ouverture au plaisir, l'espoir, le fol espoir - toutes ces nuances disent d'abord que la ville est à parcourir, à caresser, à pénéter comme un corps féminin et que, comme un tel corps, elle possède ses creux et ses points chauds. L'érotisme proprement dit (les massages, les bains, le meublé) doit être situé dans une volupté plus équivoque (SANSOT, 1984, p. 57).

Curiosamente, esta faceta sensual surge nos textos de Sá-Carneiro conjugada com a sua profunda admiração pela tumultuosa vida urbana e pelos estrondosos ruídos contemporâneos, próprios das mais avançadas sensibilidades europeias. Com efeito, no conto A Grande Sombra, sob o pretexto de que "tudo quanto me impressiona se volveu sexualizado" (SÁ-CARNEIRO, s.d., a), p. 68), o narrador exprime o apreço fervoroso pelos Grandes Meios, associando-lhes e colocando ao mesmo nível sensualidade e características da modernidade:

Eis pelo que sempre cataloguei, excitantemente e a par, os corpos nus, esplêndidos; as cidades tumultuosas 
de Europa - os perfumes, os teatros rutilantes, atapetados a roxo - as paisagens de água, ao luar - os cafés de ruído, os restaurantes de noite, as longas viagens - o murmúrio contemporâneo das fábricas, das grandes oficinas - a loucura e as bebidas geladas - (A Grande Sombra, SÁ-CARNEIRO, s.d., a), p. 68).

Verifica-se que, para o autor, a cidade está associada àquilo a que em vários textos chamará "a grande vida", entendendo-se esta como uma mistura de prazer, luxo, arte, loucura, ruído, progresso.

Finalmente, o grande fascínio de SáCarneiro pelas grandes cidades, esbanjado por todos os seus textos, talvez se encontre condensado no conto O Fixador de Instantes. Aqui encontramos a grande paixão do narrador pelas grandes capitais realizada na petrificação dentro de si de um ano passado numa delas.

Como se depreende do que acima ficou dito, o sujeito poético, o narrador e as personagens de Sá-Carneiro estabelecem com a grande cidade uma relação sexualizada. Este tipo de relação, encontramo-lo bem explicitado no conto Ressurreição, onde se destaca a utilização de vocabulário do campo erótico, atitude bem visível a propósito de Paris. De facto, para o autor e as suas personagens, Paris desempenha a função de Mulher/ Amante, assumindo-se claramente uma relação erotizada.

É sabido como a capital francesa constituiu no início do século xx o íman que atraía a maioria dos artistas portugueses e também de outras partes da Europa e do mundo.
Entretanto, o caso de Sá-Carneiro é talvez extremo em deslumbramento, é talvez o único a "arder em ouro" o seu amor por Paris: " - Paris! Paris! Orgíaco e solene, monumental e fútil..." (Ressurreição, SÁ-CARNEIRO, s.d., a), p. 201). De facto, a grande capital, a grande cidade de que fala nos seus textos é quase sempre esta cidade, "rutilante de Europa", pejada de trânsito, iluminada a jorros, povoada de mulheres fúteis e sofisticadas. Ela reúne em si todos os aspectos da "grande vida" que o fascinam e, mais ainda, os vários elementos da tão ansiada modernidade, ou, na sua concepção, da idolatrada "Europa". A quinta das "Sete Canções de Declínio" reúne grande parte desses elementos.

Face a Paris, Sá-Carneiro tem uma atitude de deslumbramento peculiar a qualquer provinciano, denominação que Pessoa lhe atribui e que o próprio reconhece. Mas a palavra "deslumbramento" é ainda insuficiente para caracterizar este tipo de relação. Com efeito, ela assume dimensões psicológicas e físicas que se enquadram na análise feita por Pierre Sansot:

L'homme concerné par une ville, l'affronte de plein fouet, esquive à peine ses coups et continue à exister dans son inévitable compagnie. [...] Cette ville n'est pas pour lui un symbole, um mot chargé de prestige. Il faut qu'il l'habite charnellement, il faut qu'il vive en sa présence, il a besoin d'elle, c'est-à-dire de son haleine, de son visage, de son ciel, de sa rumeur (SANSOT, 1984, p. 246). 
Efectivamente, a relação de Mário de Sá-Carneiro e suas personagens com Paris configura aquilo a que Claude-Gilbert Dubois chama "roman d'amour", considerando que "Habiter une ville, au sens plein du terme, c'est avoir des connivences intimes et permanentes faites d'un ensemble de petites choses. [...] Le roman d'amour à la ville superpose l'orgasme amoureux et l'extase mystique" (DUBOIS, 1989, p. 39).

A análise psicanalítica de Mitscherlich coincide também com esta teoria: "La ville est un corps que l'on peut aimer comme l'on aime un être, un ensemble tout à fait original qui englobe le paysage, la nature, les hommes qui l'ont faite, les hommes qui l'habitent aujourd'hui" (MITSCHERLICH, 1970, p. 49).

Em Mário de Sá-Carneiro, cumprindo a afirmação de que tudo o que o impressiona se lhe volve sexualizado ${ }^{27}$, também Paris se torna num corpo/objecto de prazer. Para os seus olhos/sentidos, ou das suas personagens, também elas invariavelmente envolvidas com a grande capital, Paris transforma-se quase sempre num corpo feminino, algumas vezes, masculino, mas sempre objecto de desejo.

Em "Abrigo", poema cujo assunto é exclusivamente a capital francesa, Paris assume consecutivamente o papel de mulher e de homem. Inocentemente designado, no verso inicial, de forma assexuada, por "Paris da minha ternura”, expressão corroborada por "Ó meu Paris, meu menino", é de seguida apostrofado ainda ingenuamente,

${ }^{27}$ Como diz o narrador de A Grande Sombra: "tudo quanto me impressiona se volveu sexualizado" (SÁ-CARNEIRO, s.d., a) p. 68). mas já como corpo feminino apetecido, por "Regaço de namorada,/ Meu enleio apetecido". Gradativamente, atinge no final a forma masculina, carregado de sensualidade, declaradamente objecto de desejo:

Paris - meu lobo e amigo...

- Quisera dormir contigo,

Ser todo a tua mulher!... (SÁ-

CARNEIRO, 1979, p. 126).

Também na sua correspondência, a sua relação com Paris assume o estatuto de relação homem/mulher, com o correlativo dever de fidelidade, quando em carta a Pessoa diz "confesso-lhe meu amigo eu lhe sou infiel” (SÁ-CARNEIRO, 1958, p. 222) ${ }^{28}$. Na mesma carta, utiliza outros termos que se situam também na área da sexualidade, e que, aliás, lhe são muito comuns, os verbos ter e possuir: "- apenas não seguirei coberto na vitória maior, possuindo Paris, a executar a minha obra - justamente porque estou liberto e tenho Paris!" (Ibid., p. 221).

Mais tarde, numa outra carta assume "uma saudade, uma saudade tão grande e piedosa do meu Paris de Europa, atónito, apavorado e deserto", e confessa: "Eu sinto-me em verdade a amante pequenina dum rapaz loiro que partiu para a guerra e não voltou..." (Ibid., p. 241).

Entretanto, nos textos literários este facto ganha uma dimensão ainda mais relevante. São sobretudo as suas personagens que assumem uma relação sexualizada com Paris, nomeadamente, Inácio de Gouveia, em Ressurreição, e Ricardo de Loureiro e Lúcio,

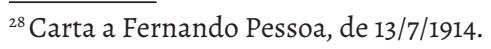


em A Confissão de Lúcio, veiculando, entretanto, os sentimentos do autor.

No conto Ressurreição, encontramos "Inácio e o pintor Jorge Pacheco [...] - sonhando repentinas fortunas mágicas, para mais purpureamente lograrem possuir a capital assombrosa..." (SÁ-CARNEIRO, s.d., a), p. 231). Neste conto, é o primeiro, Inácio de Gouveia, que "se olhava grande por tão admiravelmente sentir o seu amor por Paris, a esbater-se em saudade, longe dele - incerto de o oscilar de novo, tão cedo..." (Ibid., p. 201). Mas esta personagem vai mais longe quando assume claramente a equivalência Paris/amante, ao confessar que "Existir na grande cidade, sozinho, sem beijos - era o mesmo para o artista do que se vivesse com uma companheira garrida, suave, de carne audaciosa" (Ibid., p. 201). A cidade é assim equiparada à mulher amada.

A mesma atitude é igualmente apresentada por Ricardo de Loureiro, em A Confissão de Lúcio, que coloca Paris no lugar da amante e tem para com ela gestos próprios de qualquer apaixonado em relação ao corpo da mulher amada:

Como eu amo as suas ruas, as suas praças, as suas avenidas! [...]. E o meu próprio corpo, que elas vararam, as acompanha no seu rodopio. [...]

Ah, o que eu sofri um ano que passei longe da minha Cidade, sem esperança de me tornar a envolver nela tão cedo... E a minha saudade foi então a mesma que se tem do corpo de uma amante perdida... [...]

E à noite, num grande leito deserto, antes de adormecer, eu recordava-o ( $\operatorname{sim}$, recordava-o) como se recorda a carne nua de uma amante doirada! (SÁ-CARNEIRO, s.d., a) p. 83)

Obviamente, deveremos entender esta relação sexualizada na visão muito especial que Sá-Carneiro tem da sexualidade ${ }^{29} \mathrm{e}$ que esta mesma personagem partilha. Com efeito, também Ricardo de Loureiro desloca a sexualidade para uma área mais espiritualizada: "Não, nem é sequer a formosura que me impressiona. É outra coisa mais vaga - imponderável, translúcida: a gentileza. [...] Daí, uma ânsia estonteada, uma ânsia sexual de possuir vozes, gestos, sorrisos, aromas e cores!" (SÁ-CARNEIRO, s.d., b), p. 86).

Será esta mesma atitude que esta personagem tem em relação a Paris, impressionando-se sobretudo com a sua inexplicável "auréola", "que a envolve e a constitui em alma” (Ibid., p. 83). De qualquer forma, é por demais evidente o romance de amor entre Sá-Carneiro e Paris, o romance de que acima falámos.

O amor que tem à grande capital consubstancia-se numa relação corpo a corpo materializada nos percursos voluptuosos pelos agitados boulevards, na frequência dos inúmeros cafés, na vagabundagem pelos teatros e espectáculos de music-hall, nos convívios nos ateliers dos artistas, nos pequenos quartos alugados, equivalentes a "uma

\footnotetext{
29 "Desciam-nos só da alma os nossos desejos carnais" (SÁ-CARNEIRO, s.d., b), p. 74); "Explicam, assim, as suas singularidades sexuais pela atribuição de uma alma a tudo o que admiram e apetecem: 'Somos gente de Alma - projectamos alma a quanto admiramos, a quanto apetecemos...' (SÁ-CARNEIRO, s.d., a), p. 226). O corpo funciona como um pretexto, com valor secundário" (LOUREIRO, 1996, p. 286).
} 
garota de Paris" (Asas, SÁ-CARNEIRO, s.d., a), p. 138).

É, por assim dizer, a forma de entrelaçar a cidade consigo, como diz Ricardo de Loureiro: "Quando depois regressei à capital assombrosa, a minha ânsia foi logo de a percorrer em todas as avenidas, em todos os bairros, para melhor a entrelaçar comigo, para melhor a delirar... o meu Paris! o meu Paris!" (SÁ-CARNEIRO, s.d., b), p. 83)

$* * *$

Em conclusão, a presença do tema da cidade na escrita dos Modernistas Portugueses, como seria de esperar, ocupa um espaço vastíssimo, que seria impossível abordar aqui. Por isso, limitámo-nos a alguns pontos que, sendo significativos, apenas nos mostram algumas facetas específicas que o tratamento deste tema assume nos autores indicados. Temos plena consciência de que esta é uma mera entrada no tema e que muitas outras seriam/ são possíveis, igualmente importantes, igualmente pertinentes. É necessariamente uma escolha condicionada pelo tempo, e subjectiva, portanto.

Ainda assim, esperamos ter mostrado com esta breve e selectiva abordagem que cada um destes autores traz uma cidade dentro de si, como diria Calvino muito mais tarde, substancialmente diferente, mesmo quando se trata de uma mesma cidade real.

\section{REFERÊNCIAS}

BACHELARD, Gaston. Poétique de l'Espace. Paris: PUF, 1957.

CALVINO, Italo. As Cidades Invisíveis. Lisboa: Editorial Teorema, 1990.
DUBOIS, Claude-Gilbert. Villes-Femmes: Quelques Images Fondatrices de l'Imaginaire Urbain. In O Imaginário da Cidade. Lisboa: F. C. Gulbenkian, 1989.

LOUREIRO, La Salette. A Cidade em Autores do Primeiro Modernismo. Pessoa, Almada e Sá-Carneiro. Lisboa: Editorial Estampa, 1996. MITSCHERLICH, Alexander. Psychanalyse et Urbanisme. Paris: Gallimard, 1970.

PESSOA, Fernando. Livro do Desassossego por Bernardo Soares - $1^{a}$ Parte. Mem-Martins: Publicações Europa-América, 1986.

Livro do Desassossego por Bernardo Soares - $2^{\text {a }}$ Parte. Mem-Martins: Publicações Europa-América, 1988.

Poesia-III. Mem Martins: Publicações Europa-América, 1987.

REMY, Jean; VOYÉ, Liliane. Ville: Ordre et Violence. Paris: PUF, 1981.

ROCHA, Clara. Revistas Literárias do Século XX em Portugal: Lisboa: Imprensa NacionalCasa da Moeda, 1985.

SÁ-CARNEIRO, Mário de. Cartas a Fernando

Pessoa. Lisboa: Ática, 1958, 2 vols.

Cartas Escolhidas, Mem Martins:

Publicações Europa- América, 1992, 2 vols.

Céu em Fogo. Mem Martins:

Publicações Europa-América, s.d., a)

A Confissão de Lúcio. Mem Martins:

Publicações Europa-América, s.d., b)

Poesias. Lisboa: Círculo de Leitores, 1979.

SANSOT, Pierre. Poétique de la Ville. Paris: Méridiens Klincksieck, 1984.

Recebido para publicação em 14 jan. 2017.

Aceito para publicação em 30 jan. 2017. 